\title{
KATEGORI NYERI DISMENOREA PADA SANTRI PUTRI DI PONDOK PESANTREN AL- AMIN
}

\author{
Siti Haniyah ${ }^{1}$, Dwi Novitasari ${ }^{2}$ \\ ${ }^{1}$ Prodi Keperawatan S1 STIKes Harapan Bangsa Purwokerto \\ haniwiyana56@gmail.com \\ ${ }^{2}$ Prodi Keperawatan S1 STIKes Harapan Bangsa Purwokerto \\ dwinovitasari1110@gmail.com
}

\begin{abstract}
Pain Dysmenorrhea is a physiological condition that will generally be experienced by women who are menstruating. Painful menstruation or dysmenorrhea is a manifestation of the uterine muscle contraction dysmenorrhea Pain management is very important. Relaxation of dysmenorrhea pain is very important. The purpose of this study was to determine the pain of dysmenorrhea in female students in Pondok Pesantren Darrussalam Purwokerto.

This is quasi Description Design by using sample 30 respondent The Aims of this Research was to know description of pain at dysmenorrhea at female students in Pondok Pesantren Al amin Purwokerto. Result of this study is the pain of dysmenorrhea in female students in Pondok Pesantren Darrussalam Purwokerto is heavy pain.
\end{abstract}

Key Word: Description Dysmenorrhea

\section{PENDAHULUAN}

Nyeri Dismenore adalah kondisi fisiologis yang secara umum akan dialami oleh wanita yang sedang menstruasi . Rasa nyeri adalah manifestasi dari adanya kontraksi otot rahim . Kontraksi inilah yang menimbulkan rasa sakit pada daerah perut dan menyebabkan pengeluaran darah akibat luruhnya dinding endometrium. Dengan adannya kontraksi inilah darah akan keluar dan menstruasi berlangsung dengan normal. Angka kejadian dismenore sebesar $64,25 \%$ yang terdiri dari $54,89 \%$ dismenore primer dan 9,36\% dismenore sekunder. Di Surabaya didapatkan $1,07-1,31 \%$ dari jumlah penderita dismenore datang lagi kebagian kebidanan (Ernawati, 2010).

Upaya penatalaksanaan nyeri pada dismenore adalah dengan menggunakan farmakologis dan non-farmakologis. Pengendalian nyeri secara farmakologi efektif untuk nyeri sedang dan berat. Namun demikian pemberian farmakologi tidak bertujuan untuk meningkatkan kemampuan klien sendiri untuk mengontrol nyerinya (Van Kooten, 1999 dalam Anggorowati dkk., 2007). Sehingga dibutuhkan kombinasi farmakologi untuk mengontrol nyeri dengan non farmakologi agar sensasi nyeri dapat berkurang serta masa pemulihan tidak memanjang (Bobak, 2005).

Manajemen nonfarmakologi yang sering diberikan antara lain yaitu dengan meditasi, latihan autogenic, latihan relaksasi progresif, guided imagery, nafas ritmik, operant conditioning, biofeedback, membina hubungan terapeutik, sentuhan terapeutik, stimulus kutaneus, hipnosis, musik, 
accupresure, aromaterapi (Sulistyowati, 2009).

Di Pondok Pesantren $\mathrm{Al}$ amin penanganan nyeri dismenore menggunakan pendekatan farmakologi, biasanya dengan diberikan analgetik (asam mefenamat), namun penggunaan analgesik secara terus menerus dapat mengakibatkan ketagihan obat. Hal ini membutuhkan penanganan yang tepat sehingga di perlukan adanya penelitian mengenai gambaran nyeri dismenore pada santri putri sehingga penanganan non farmakologisnya bisa ditetapkan dengan tepat sesuai tingkat yang dirasakan

Berdasarkan latar belakang dan studi pendahuluan tersebut, peneliti tertarik untuk mengambil judul penelitian "Gambaran nyeri Dismenore di Pondok Pesantren Al Amin Purwokerto".

\section{METODEPENELITIAN}

Desain Penelitian ini adalah Deskriptif dengan menggunakan sampel 30 responden dengan Lokasi penelitian di Pondok Pesantren Al Amin Purwokerto. Responden pada penelitian ini adalah Santri yang mengalami nyeri dismenore di Pondok Pesantrean Al Amin Purwokerto Timur pada periode penelitian berlangsung, dengan kriteria sebagai berikut: bersedia menjadi responden, dengan Dismenore. Rumus besar sample dalam penelitian ini dengan rumus issac dan Michel dimana didapatkan jumlah responden dalam penelitian ini berjumlah 30 responden. Teknik sampling yang digunakan pada penelitian ini adalah quota Sampling dengan cara santri putri Stikes di Pondok Pesantrean
Al Amin Purwokerto Timur yang mengalami nyeri Dismenore pada saat penelitian berlangsung dengan kriteria inklusi: santri yang mengalami dismenore primer dan ada di tempat penelitian saat penelitian berlangsung kriteria ekslusi disminore sekunder.

Teknik pengumpulan data yang digunakan pada penelitian ini adalah penilaian skala nyeri pada saat dismenore menggunakan skala nyeri Numeric Rating Scale. Metode analisis data yang digunakan pada penelitian ini meliputi analisi univariat. Analsis univariat untuk mendapatkan gambaran/ deskriptif dari masing-masing variabel penelitian. Analisis univariat meliputi mean, modus, median, nilai minimal dan maksimal, standar deviasi.

\section{HASIL}

\section{a. Tingkat Nyeri Dismenore}

Tabel 1.1 Analisis Des kriptif Berdasarkan Tingkat Nyeri

\begin{tabular}{|c|c|c|c|c|}
\hline Variabel & $\begin{array}{c}\text { Mean } \\
\text { (mmHg) }\end{array}$ & $\begin{array}{c}\text { Std Deviasi } \\
\text { (mmHg) }\end{array}$ & $\begin{array}{c}\text { Min } \\
(\mathrm{mmHg})\end{array}$ & $\begin{array}{c}\text { Max } \\
(\mathrm{mmHg})\end{array}$ \\
\hline Tingkat Nyeri 30 & 2,6 & 0,18 & 2 & 4 \\
\hline
\end{tabular}

Berdasarkan tabel di atas dapat diketahui rata-rata tingkat nyeri dismenore yaitu 2,6. Rata-rata tingkat nyeri dismenore tersebut termasuk kategori nyeri ringan. Skala nyeri dismenore bisa saja sudah turun karena dipondok pesantren al Amin pernah di lakukan penelitian serupa mengenai pengaruh senam dismenore terhadap nyeri dismenore. 


\section{SIMPULAN DAN SARAN}

\section{a.Simpulan}

Rata-rata tingkat nyeri dismenore termasuk kategori nyeri ringan.

\section{b. Saran}

Peneliti selanjutnya dapat mengembangkan penelitian ini dengan membandingkan mempertimbangkan skala nyeri awal sebelum perlakuan sehingga penanganan nyerinya bisa tepat.

\section{DAFTAR PUSTAKA}

Arikunto. S. (2006). Prosedur Penelitian Suatu Pendekatan Praktik. Jakarta: Rineka Cipta.

Atkinson, R (2003). Penghantar Psikologi Edisi 8 Jilid 2. Jakarta: Penerbit Erlangga.

Berman, A,. (2009). Buku Ajar Praktik Keperawatan Klinis (Ed. 5). Jakarta : EGC.

Bird, J. (2006). Autogenic therapy. International therapist Issue.

Black, J.M., \& Hawks, J.H. (2005). Medical surgical nursing : Clinical management for positive outcome (vols. 1-2. 7 ed). Missouri : elsevier saunders.

Bobak, M. I, (2005). Buku Ajar Keperawatan Maternitas (Ed. 4). Jakarta : EGC

Cunningham, G. F, et.al. (2006). Obstetri William, (Ed. 21). Jakarta : EGC

Farrer, Helen. (2011). Perawatan Maternitas (Ed. 2). Jakarta : EGC

Laila. (2011). Buku Pintar Menstruasi. Yogyakarta: Bukubiru

Lukman, TV. (2013). Pengaruh Teknik Relaksasi Nafas Dalam Terhadap Intensitas Nyeri Pada Pasien Post Operasi Nyeri Dismenore Di RSUD Prof. Dr. Hi. Aloei Saboe


http://kim.ung.ac.id/index.php/KI MFIKK/article/viewFile/2859/28 35 Diakses 23 November 2013 Jam 10.07 WIB
Mochtar, R. (2008). Sinopsis Obstetri. Jakarta :EGC

Notoatmodjo, S. (2010). Metodologi Penelitian Kesehatan. Jakarta: Rineka Cipta.

Potter \& Perry. (2005). Buku Ajar Fundamental Keperawatan Konsep, Proses, Dan Praktik (Ed.4, Vol 1). Jakarta : EGC.

Prawirohardjo, S. (2009). Ilmu Kebidanan. Jakarta : PT. Bina Pustaka

Price \& Wilson. (2006). Patofisiologi: Konsep Klinis Proses Penyakit. Ed. 6. Vol- 2. Jakarta: EGC

Saunders, S. (2006). Autogenic therapy: short term therapy for long term gain.Positive Health.

Smeltzer \& Bare. (2013). Keperawatan Medikal Bedah: Buku ajar.Edisi 8.Jakarta: $\quad P$ enerbit $B u k u$ Kedokteran:EGC 